\title{
A pH-responsive water-soluble cyclic polymer
}

Zhihui Miao, Tomohiro Kubo, Digvijayee Pal, Brent S. Sumerlin,* and Adam S. Veige*

Center for Catalysis, Department of Chemistry, University of Florida, P.O. Box 117200, Gainesville, Florida 32611, United States

Center for Macromolecular Science \& Engineering and George \& Josephine Butler Polymer Research Laboratory, Department of Chemistry, University of Florida, P.O. Box 117200, Gainesville, Florida 32611, United States

\section{Table of Contents}

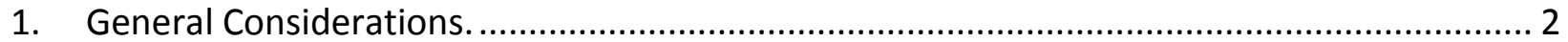

2. Synthesis of cyclic poly(4-ethynylanisole) ................................................................... 3

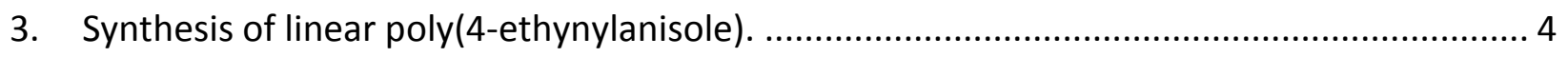

4. Synthesis of cyclic and linear poly(4-ethynylphenol). .................................................... 4

5. NMR spectroscopic data for cyclic poly(4-ethynylanisole), linear poly(4-thynylanisole), cyclic poly(4-ethynylphenol) and linear poy(4-ethynylphenol) .............................................. 5

6. SEC analysis of cyclic and linear poly(4-ethynylanisole). ............................................. 9

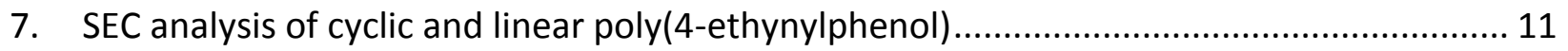

8. Responsive solubility of cyclic and linear poly(4-ethynylphenol) .................................. 13 


\section{General Considerations.}

Unless specified otherwise, all manipulations were performed under an inert atmosphere using glove-box or Schlenk line techniques. Tetrahydrofuran (THF), dichloromethane (DCM) and toluene were dried using a GlassContour drying column. 4-Ethynylanisole was purchased from Sigma-Aldrich, dried over calcium hydride, distilled, degassed by freeze pump thawing, and filtered through a column of basic alumina prior to use. Complex 1 was prepared according to literature procedures. ${ }^{1}$ Boron tribromide and acetylacetonato-1,5-cyclooctadienerhodium $(\mathrm{I})^{2}$ were used as purchased. NMR spectra were obtained on Mecury $300 \mathrm{MHZ}$, Varian INOVA 500 MHZ and Varian INOVA2 $500 \mathrm{MHz}$ spectrometers. Chemical shifts are reported in $\delta(\mathrm{ppm})$. For

${ }^{1} \mathrm{H}$ and ${ }^{13} \mathrm{C}$ NMR spectra, the residual solvent peaks were used as an internal reference standard. Data are reported as follows: chemical shift, multiplicity $(s=$ singlet, $d=$ doublet, $t=$ triplet, $q=$ quartet, $d d=$ doublet of doublets, $\mathrm{m}=$ multiplet, $\mathrm{b}=$ broad) and integration. Molecular weights, molecular weight distributions, viscosities, and radii of gyration were determined by gelpermeation chromatography with tetrahydrofuran (THF) as the mobile phase at $35^{\circ} \mathrm{C}$ at a flow rate of $1.0 \mathrm{~mL} / \mathrm{min}$ (Agilent isocratic pump, degasser, and autosampler; columns: three PLgel 5 $\mu \mathrm{m}$ MIXED-D mixed bed columns, molecular weight range $200-400000 \mathrm{~g} / \mathrm{mol}$ ). For some of the polymers, molecular weights and molecular weight distributions were measured via multi-angle laser light scattering size exclusion chromatography (MALS-SEC) in N,N-dimethylacetamide (DMAc) with $50 \mathrm{mM} \mathrm{LiCl}$ at $50^{\circ} \mathrm{C}$ and a flowrate of $1.0 \mathrm{~mL} / \mathrm{min}$ (Agilent isocratic pump, degasser, and autosampler; ViscoGel I-series $10 \mu \mathrm{m}$ guard column and two ViscoGel I-series G3078 mixed bed columns, with molecular weight ranges from 0-20×103 and 0-10×106 g/mol, respectively). Detection consisted of a Wyatt Optilab T-rEX refractive index detector operating at $658 \mathrm{~nm}$, a 
Wyatt miniDAWN Treos light scattering detector operating at $656 \mathrm{~nm}$, and a Wyatt ViscoStar-II viscometer. Absolute molecular weights and molecular weight distributions were calculated using the Wyatt ASTRA software.UV-vis spectra were obtained with Varian Cary 100 UV-vis spectrometer (Agilent Technologies, Santa Clara, CA, USA). Fourier transform infrared spectroscopy was done using Cary 630 FTIR (Agilent Technologies, Santa Clara, CA, USA). The $\mathrm{pH}$ values of the solutions were obtained with a $\mathrm{pH}$ meter (UB-5, Denver Instrument).

\section{Synthesis of cyclic poly(4-ethynylanisole).}

$\mathrm{n}$<smiles>C#Cc1ccc(OC)cc1</smiles>

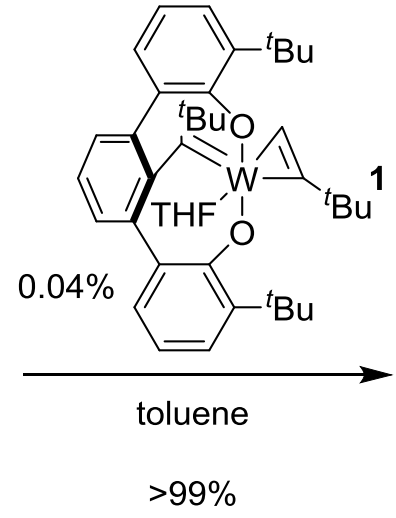

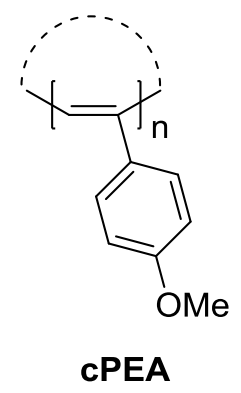

In an inert atmosphere glovebox, $1 \mathrm{~mL}$ of toluene was added to a glass vial equipped with a stir bar. $98.4 \mu \mathrm{L}$ of 4 -ethynylanisole $(0.76 \mathrm{mmol})$ was added via micropipette. $190.0 \mu \mathrm{L}$ of a stock solution of catalyst $1(0.002 \mathrm{mmol} / \mathrm{mL})$ was added into the stirring solution via micropipette in one shot. The solution turned red-orange. The polymerization was quenched after 30 min by dropwise adding the solution into tenfold excess of stirring methanol. The precipitated polymer was collected via vacuum filtration and dried under vacuum (Yield $=99 \%) .{ }^{1} \mathrm{H} N M R(300 \mathrm{MHz}$, $\left.\mathrm{CDCl}_{3}, \delta(\mathrm{ppm})\right):$ 7.2-6.1 (b, 4H, Ar-H), 6.1-5.6 (bs, $\left.1 \mathrm{H}, \mathrm{CH}=\right), 4.0-3.2\left(\mathrm{~s}, 3 \mathrm{H}, \mathrm{OCH}_{3}\right) .{ }^{13} \mathrm{C} \mathrm{NMR}(500$ 
$\left.\mathrm{MHz}, \mathrm{CDCl}_{3}, \delta(\mathrm{ppm})\right): 158.8\left(\mathrm{~s}, \mathrm{Ar}-\mathrm{C}-\mathrm{OCH}_{3}\right), 139.1$ (s, Ar- $\left.\mathrm{C}_{\text {para }}-\mathrm{C}=\right)$ ) 135.9 (s, Ar-C=), 130.5 (s, Ar$\left.\mathrm{C}_{\text {ortho }}\right), 129.0$ (s, Ar- $\left.\mathrm{C}_{\text {meta }}\right), 113.3(\mathrm{~s}, \mathrm{CH}=), 55.3\left(\mathrm{~s}, \mathrm{OCH}_{3}\right)$.

\section{Synthesis of linear poly(4-ethynylanisole).}

$\mathrm{n}$<smiles>C#Cc1ccc(OC)cc1</smiles>

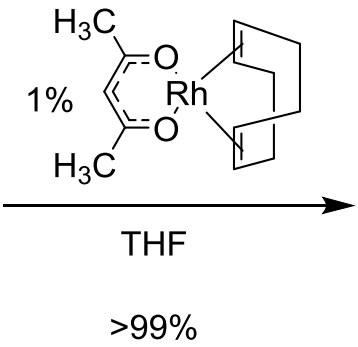

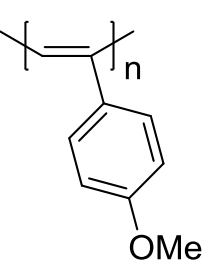

PEA

In an inert atmosphere glovebox, $1 \mathrm{~mL}$ of tetrahydrofuran was added to a glass vial equipped with a stir bar. $98.2 \mu \mathrm{L}$ 4-ethynylanisole $(0.75 \mathrm{mmol})$ was added via micropipette. $257.2 \mu \mathrm{L}$ of a stock solution of acetylacetonato-1,5-cyclooctadienerhodium(I) $(0.025 \mathrm{mmol} / \mathrm{mL})$ was added into the stirring solution via micropipette in one shot. The solution turned yellow. The polymerization was quenched after $2 \mathrm{~h}$ by dropwise adding the solution into tenfold excess of stirring methanol. The precipitated polymer was collected via vacuum filtration and dried under vacuum (Yield = 99\%). ${ }^{1} \mathrm{H}$ NMR $\left(300 \mathrm{MHz}, \mathrm{CDCl}_{3}, \delta(\mathrm{ppm})\right)$ : 6.8-6.5 (bd, $\left.2 \mathrm{H}, \mathrm{Ar}-\mathrm{H}\right), 6.5-6.2(\mathrm{bd}$, $2 \mathrm{H}, \mathrm{Ar}-\mathrm{H}), 5.8-5.6(\mathrm{bs}, 1 \mathrm{H}, \mathrm{CH}=\mathrm{C}), 3.7-3.3\left(\mathrm{~s}, 3 \mathrm{H}, \mathrm{OCH}_{3}\right) .{ }^{13} \mathrm{C} \mathrm{NMR}\left(500 \mathrm{MHz}, \mathrm{CDCl}_{3}, \delta(p p m)\right)$ : $158.6\left(\mathrm{~s}, \mathrm{Ar}-\mathrm{C}-\mathrm{OCH}_{3}\right), 138.7$ (s, Ar- $\left.\mathrm{C}_{\text {para }}-\mathrm{C}=\right)$ ) 135.8 (s, Ar-C=), 130.2 (s, Ar-Cortho), 128.7 (s, Ar$\left.\mathrm{C}_{\text {meta }}\right), 113.1(\mathrm{~s}, \mathrm{CH}=), 55.2\left(\mathrm{~s}, \mathrm{OCH}_{3}\right)$.

\section{Synthesis of cyclic and linear poly(4-ethynylphenol).}

In a $50 \mathrm{~mL}$ two neck round bottom flask equipped with a stir bar, $50 \mathrm{mg}$ PEA was added and dissolved with $15 \mathrm{~mL}$ anhydrous methylene chloride. The polymer solution was kept under Argon and cooled in ice bath for $15 \mathrm{~min} .0 .25 \mathrm{~mL}$ boron tribromide was added via a syringe. The 
reaction was then brought to room temperature and stirred under Argon for $3 \mathrm{~h}$. The reaction was quenched in an ice bath by dropwise adding methanol. The solution was concentrated and then drop-wise added into tenfold excess of stirring hexanes. A purple polymer precipitated and was collected via vacuum filtration and dried under vacuum (Yield $=95 \%) .{ }^{1} \mathrm{H}$ NMR (300 $\left.\mathrm{MHz}, \mathrm{DMSO}-d_{6}, \delta(\mathrm{ppm})\right):$ 7.6-5.2 (b, 5H, Ar-H and - $\left.\mathrm{CH}=\right), 1.64\left(\mathrm{~s}, 1 \mathrm{H},-\mathrm{OH}\right.$ exchanging with $\left.\mathrm{H}_{2} \mathrm{O}\right)$.

${ }^{13}$ C NMR signals are too broad to interpret.

5. NMR spectroscopic data for cyclic poly(4-ethynylanisole), linear poly(4-thynylanisole), cyclic poly(4-ethynylphenol) and linear poy(4-ethynylphenol)
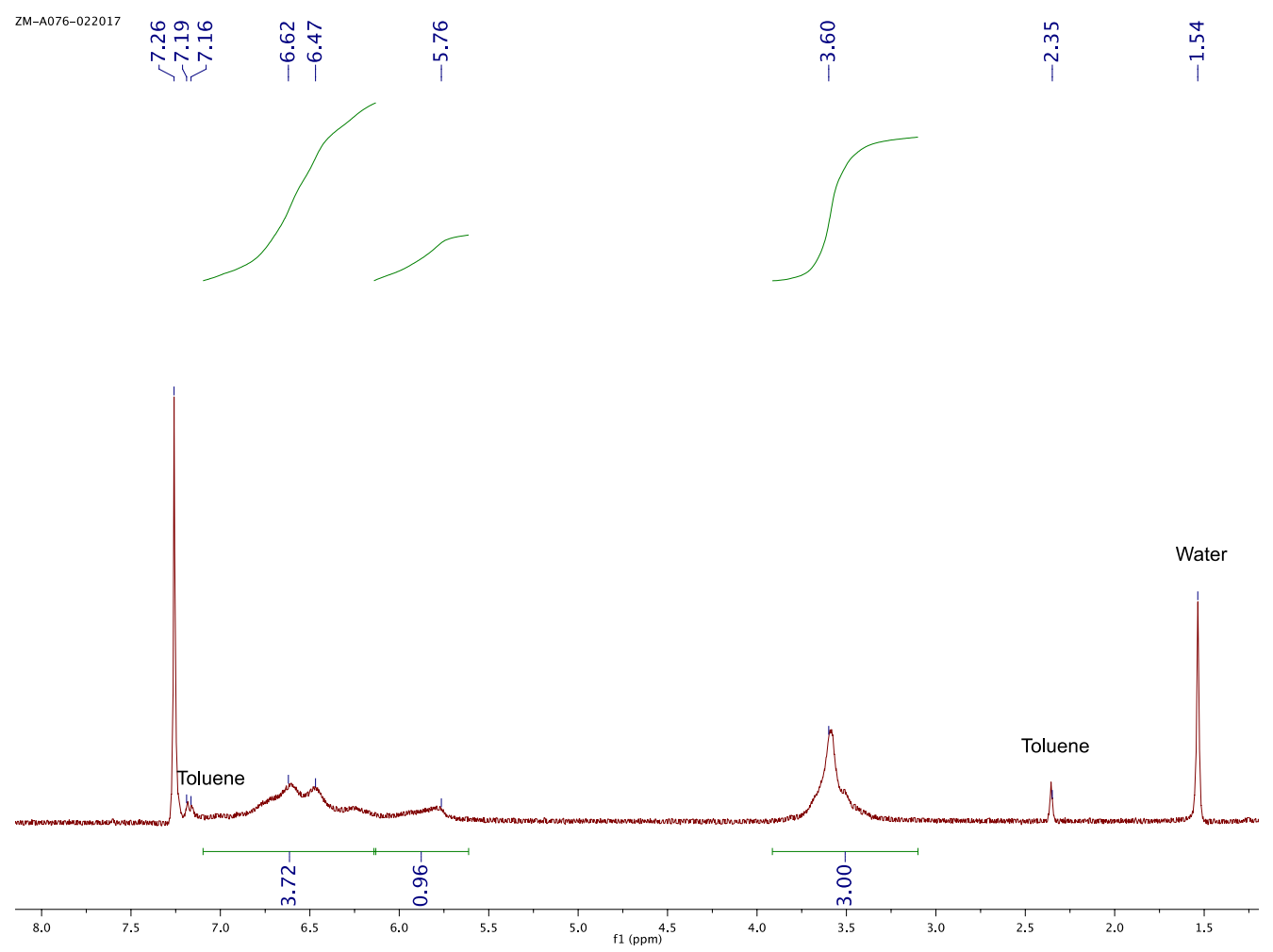

Figure S1. ${ }^{1} \mathrm{H}$ NMR spectra of cyclic poly(4-ethynylanisole) in $\mathrm{CDCl}_{3}$ at $25^{\circ} \mathrm{C}$. 


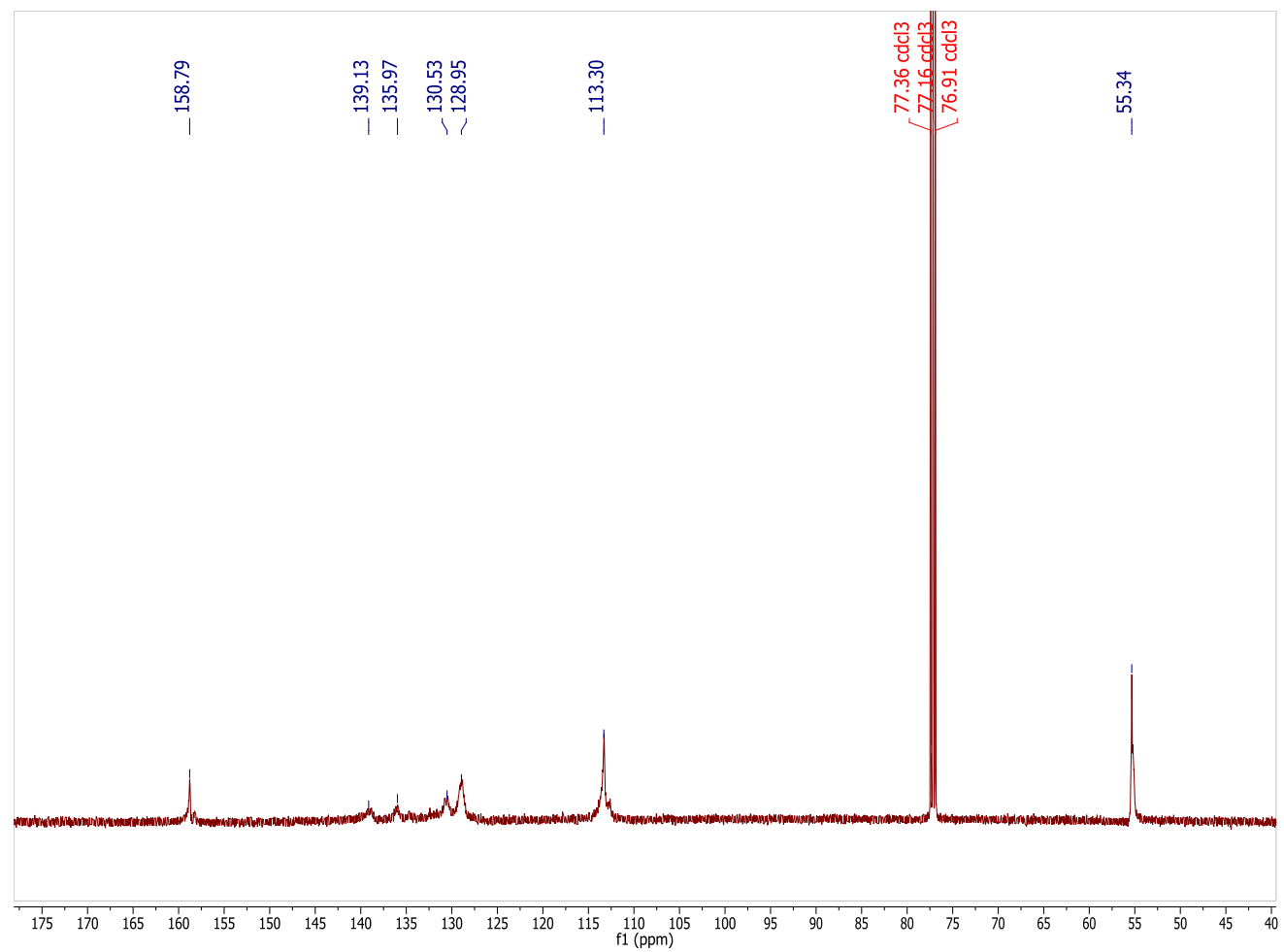

Figure S2. ${ }^{13} \mathrm{C}$ NMR spectra of cyclic poly(4-ethynylanisole) in $\mathrm{CDCl}_{3}$ at $25^{\circ} \mathrm{C}$.

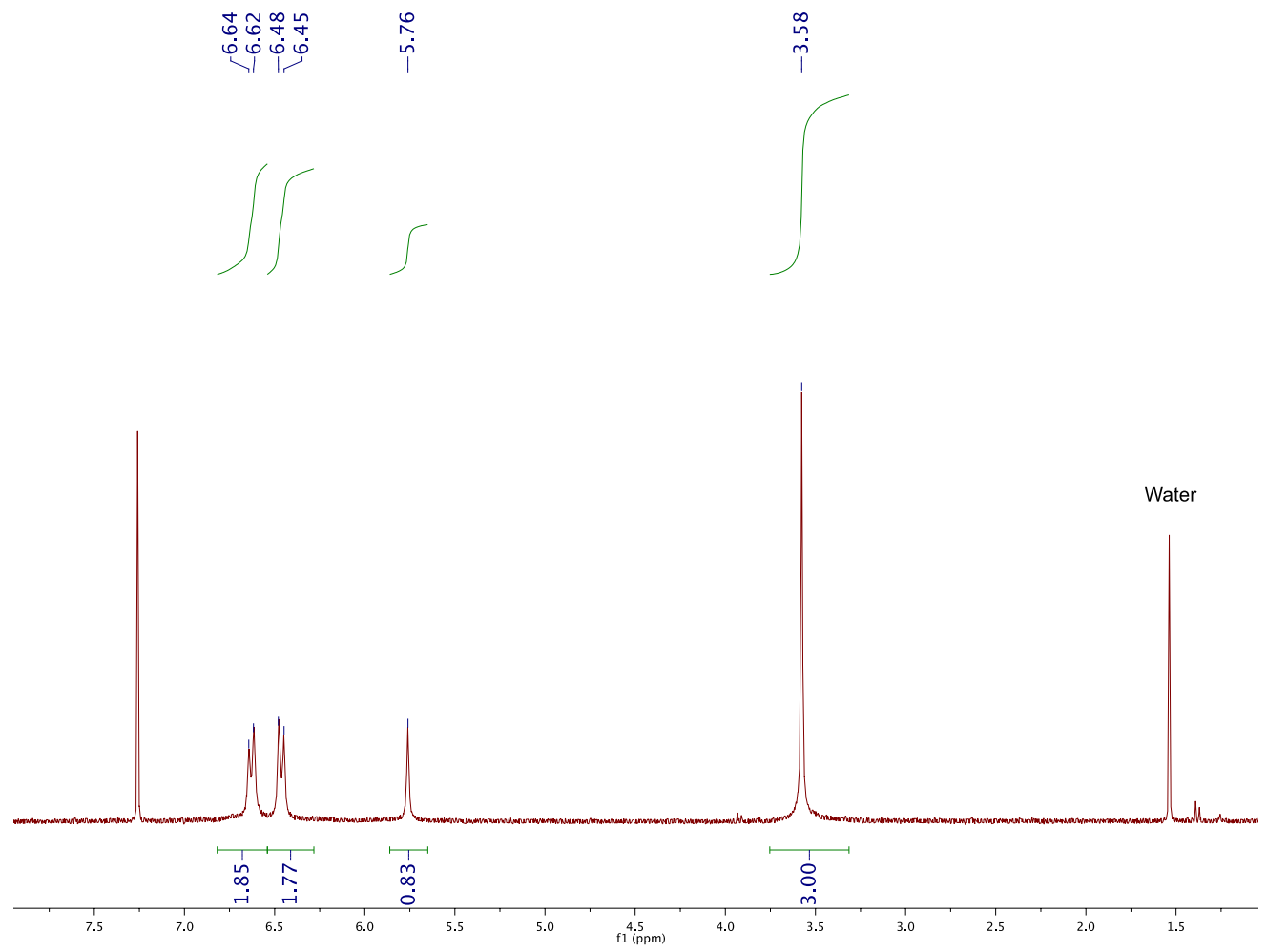


Figure S3. ${ }^{1} \mathrm{H}$ NMR spectra of linear poly(4-ethynylanisole) in $\mathrm{CDCl}_{3}$ at $25^{\circ} \mathrm{C}$.

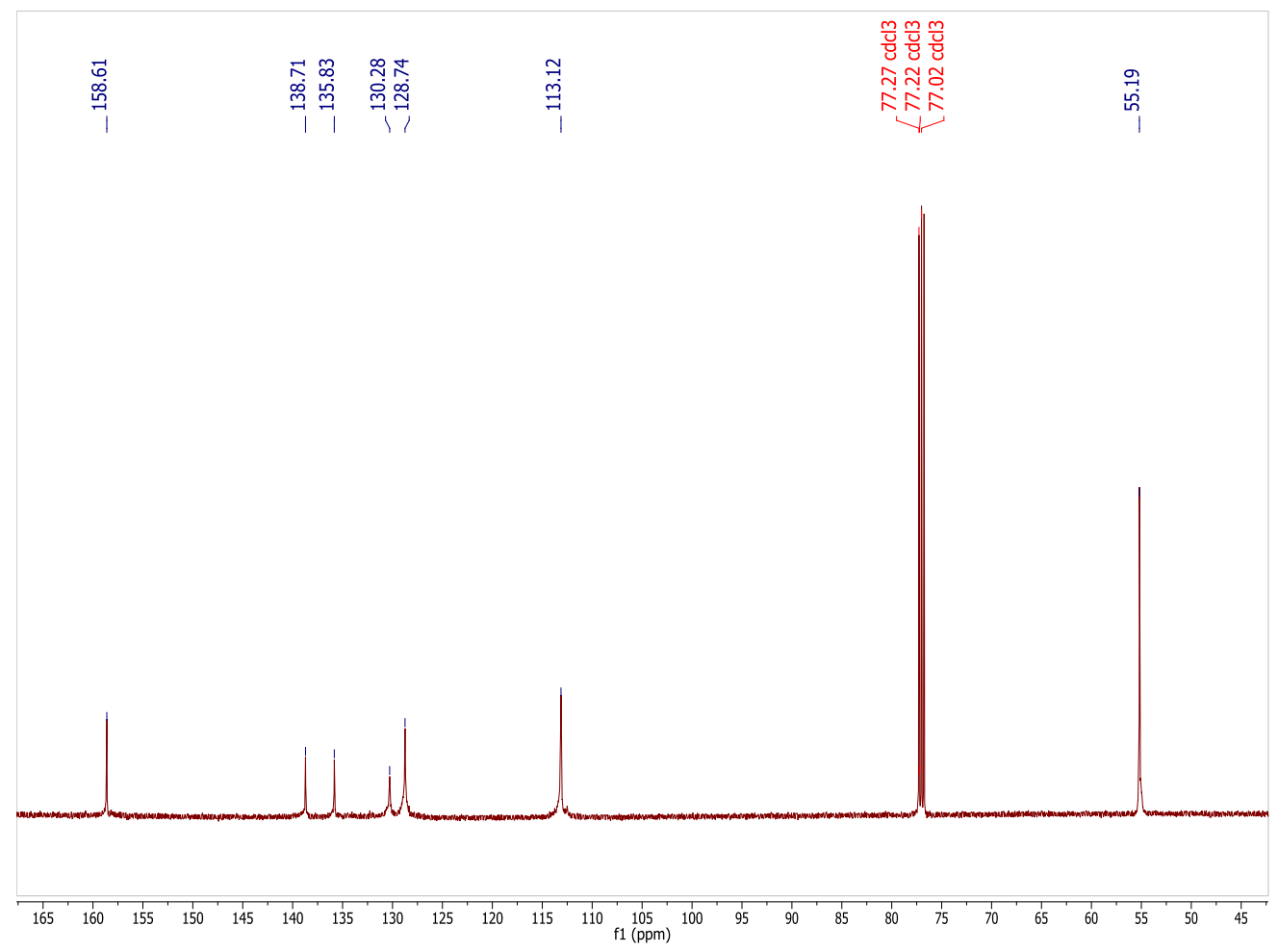

Figure S4. ${ }^{13} \mathrm{C}$ NMR spectra of linear poly(4-ethynylanisole) in $\mathrm{CDCl}_{3}$ at $25^{\circ} \mathrm{C}$. 


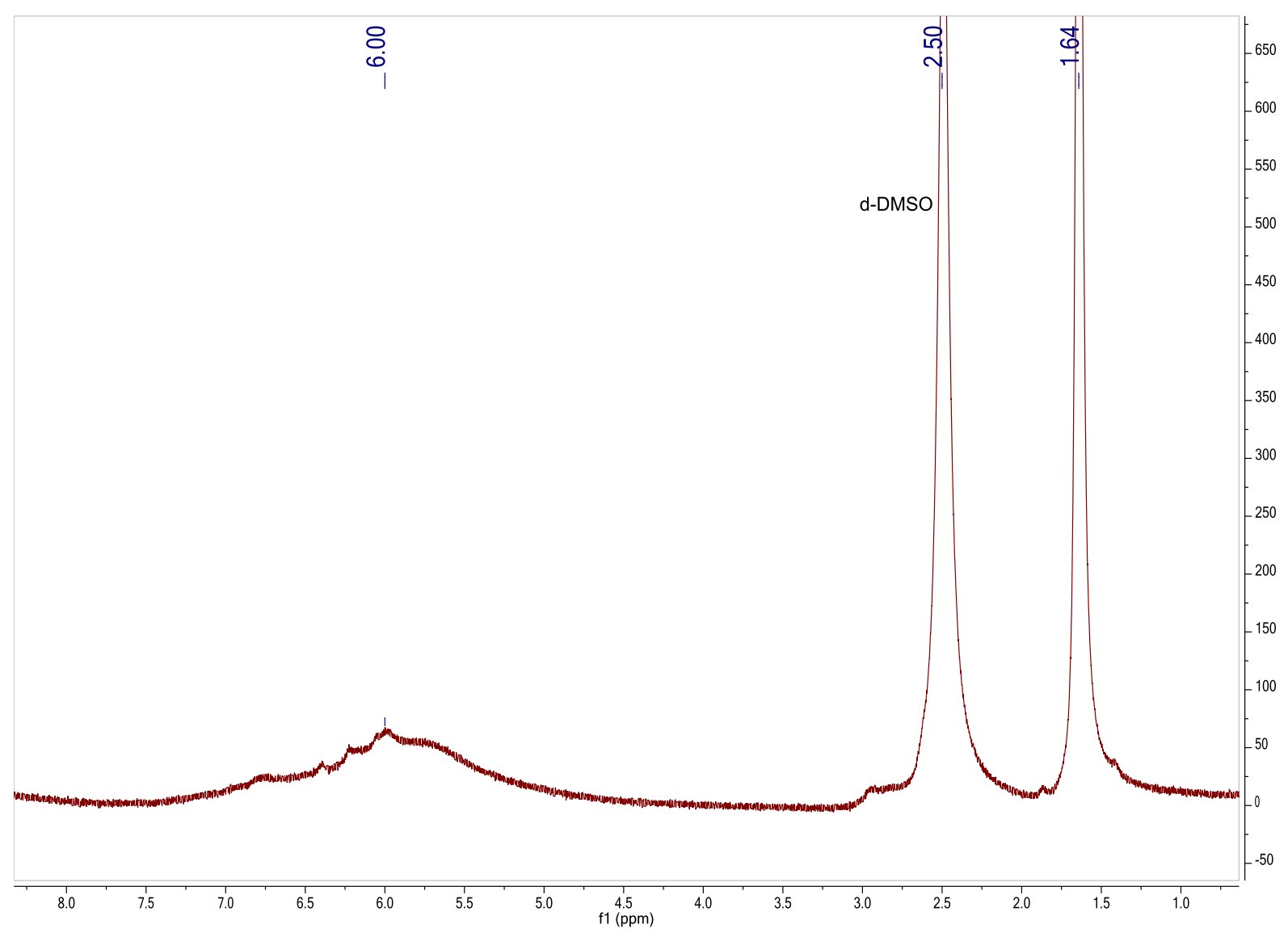

Figure S5. ${ }^{1} \mathrm{H}$ NMR spectra of cyclic poly(4-ethynylphenol) in DMSO- $d_{6}$ at $25^{\circ} \mathrm{C}$. 


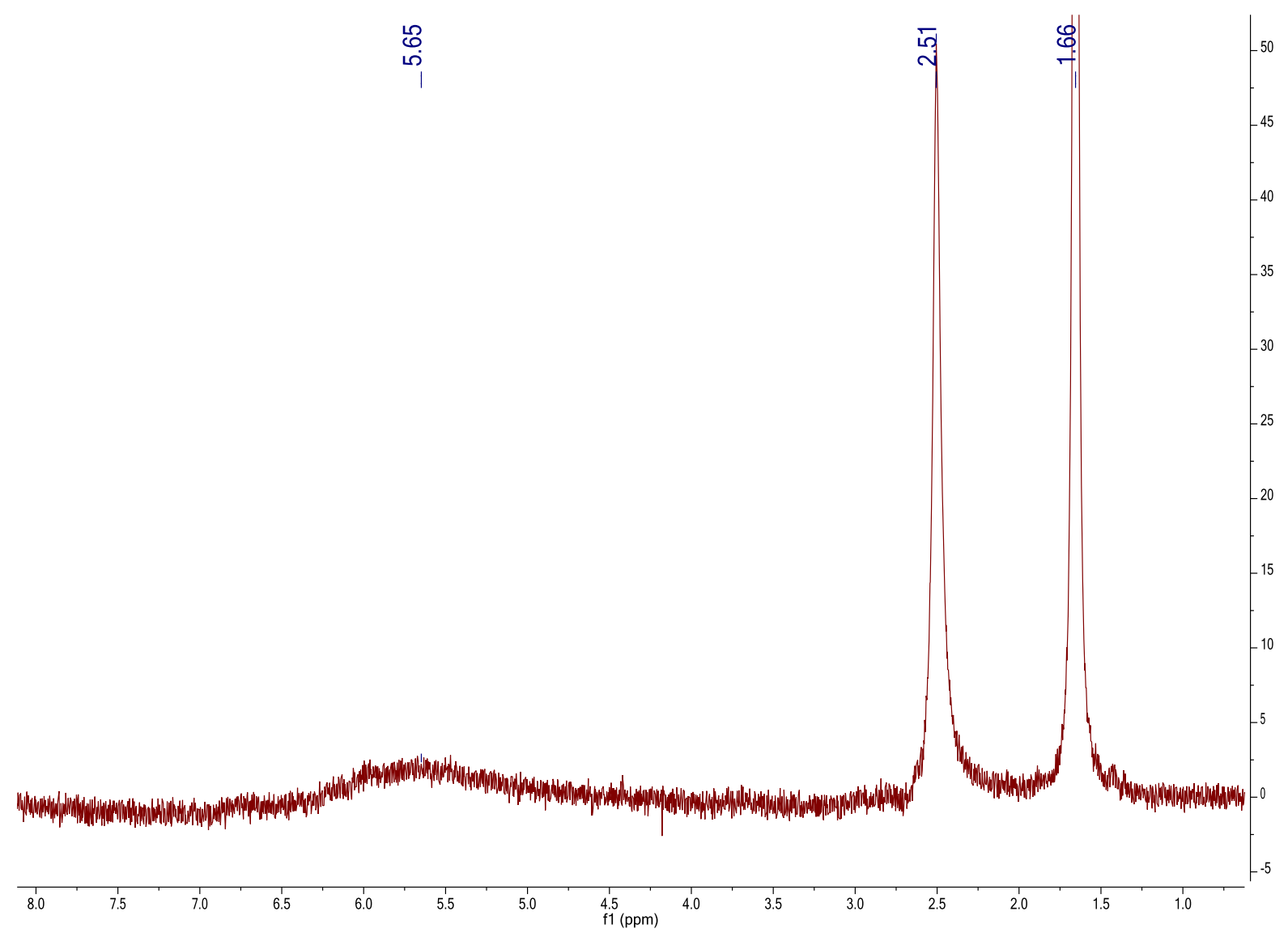

Figure S6. ${ }^{1} \mathrm{H}$ NMR spectra of cyclic poly(4-ethynylphenol) in DMSO- $d_{6}$ at $25^{\circ} \mathrm{C}$.

\section{SEC analysis of cyclic and linear poly(4-ethynylanisole).}

The absolute molecular weight averages and distribution of the polymer samples were measured by size-exclusion chromatography and summarized in Table S1. 5.0mg polymer sample was dissolved $0.889 \mathrm{~g}(1.00 \mathrm{~mL})$ THF. The $\mathrm{dn} / \mathrm{dc}$ value was measured using $100 \%$ mass recovery method with the exact concentration of the polymer solution. The GPC trace of cyclic and linear poly(4-ethynylanisole) is depicted in Figure S7 and S8, respectively. The same dn/dc value is applied to cyclic and linear poly(4-ethynylanisole) to compare the difference in the radius of gyration $\left.\left(<R_{\mathrm{g}}{ }^{2}\right\rangle\right)$ and intrinsic viscosity of cyclic and linear poly(4-ethynylanisole). The 
plots of the radius of gyration $\left(R_{g}\right)$ vs. MM and intrinsic viscosity vs. MM are included in Figure 3 and 4 (main article).

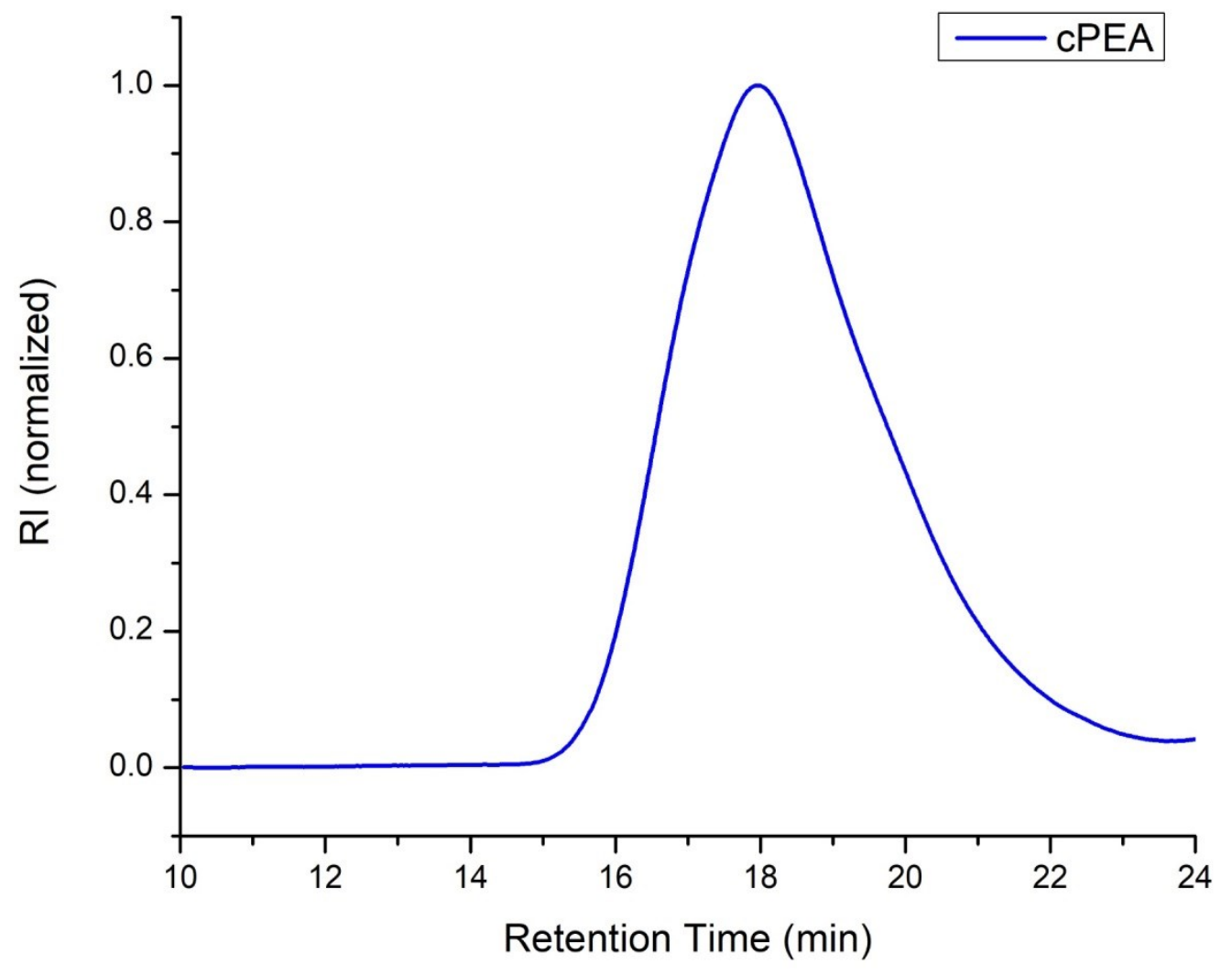

Figure S7. GPC trace of cyclic poly(4-ethynylanisole) in THF. 


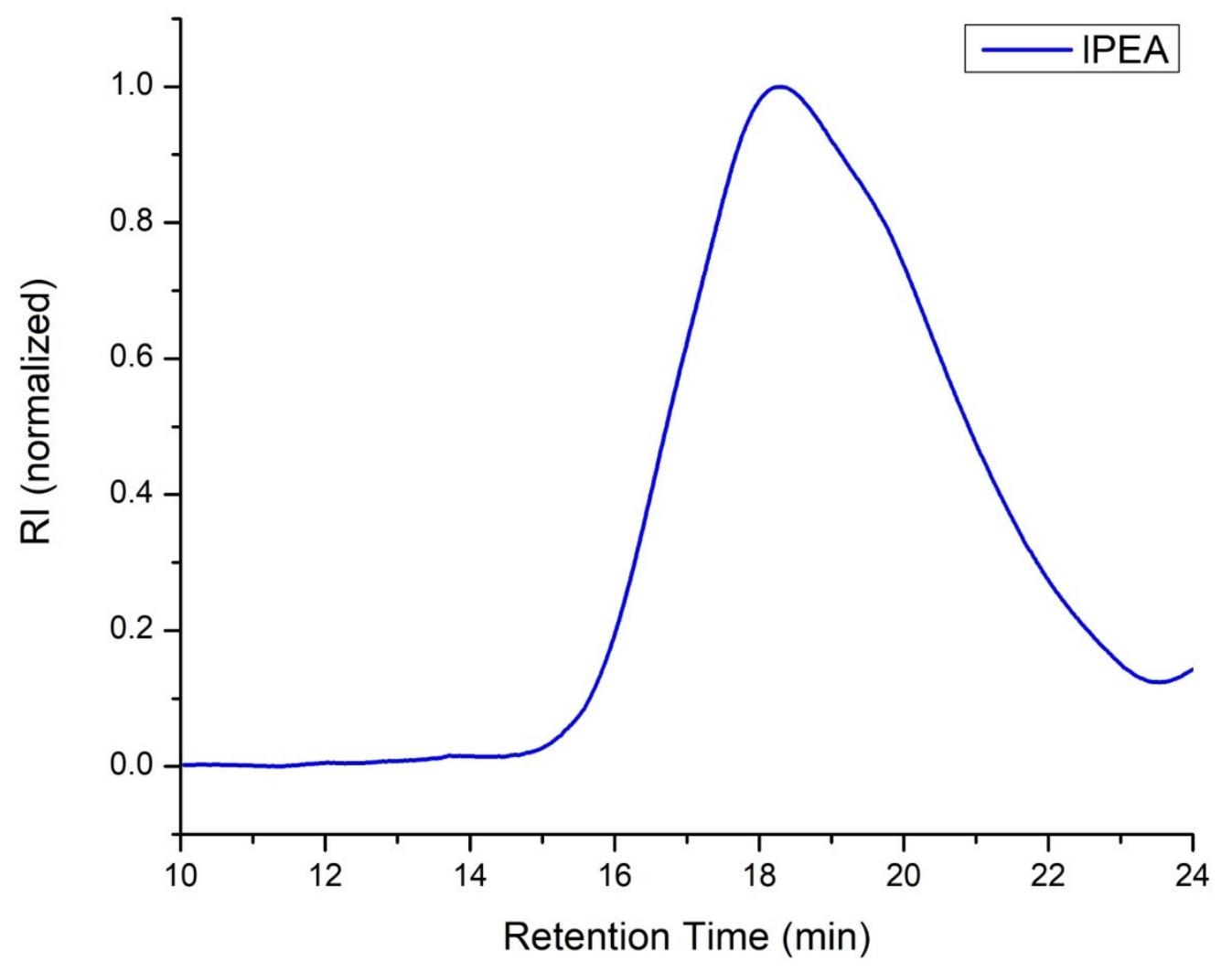

Figure S8. GPC trace of linear poly(4-ethynylanisole) in THF.

\section{SEC analysis of cyclic and linear poly(4-ethynylphenol)}

The absolute molecular weight averages and distribution of the polymer samples were measured by size-exclusion chromatography and summarized in Table S1. 5.0 mg polymer sample was dissolved in around $0.940 \mathrm{~g}(1.00 \mathrm{~mL})$ dimethylacetamide. The $\mathrm{dn} / \mathrm{dc}$ value was measured using $100 \%$ mass recovery method with the exact concentration of the polymer solution. The GPC trace of cyclic and linear poly(4-ethynylanisole) is depicted in Figure S9 and S10, respectively. 


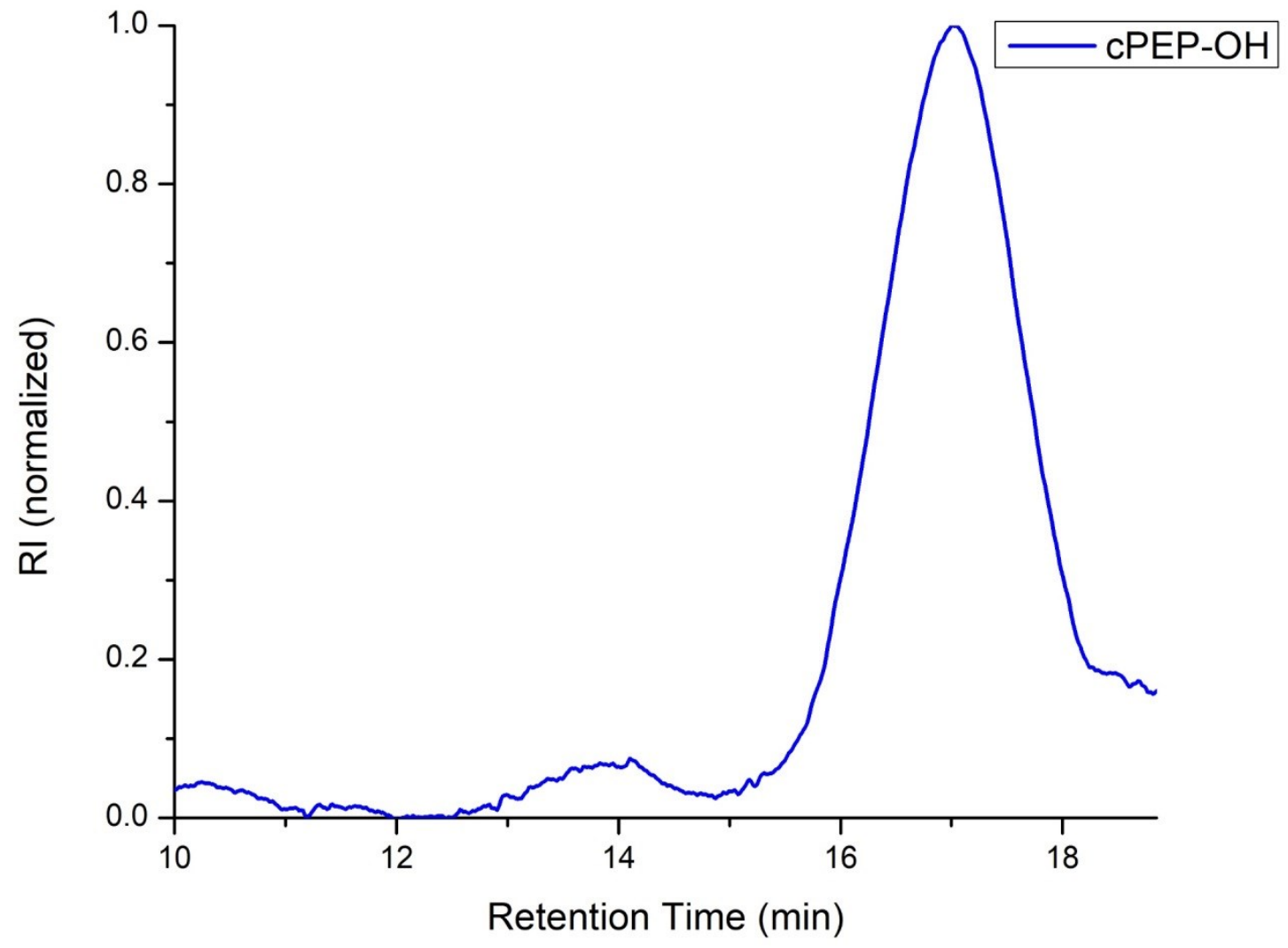

Figure S9. GPC trace of cyclic poly(4-ethynylphenol). 


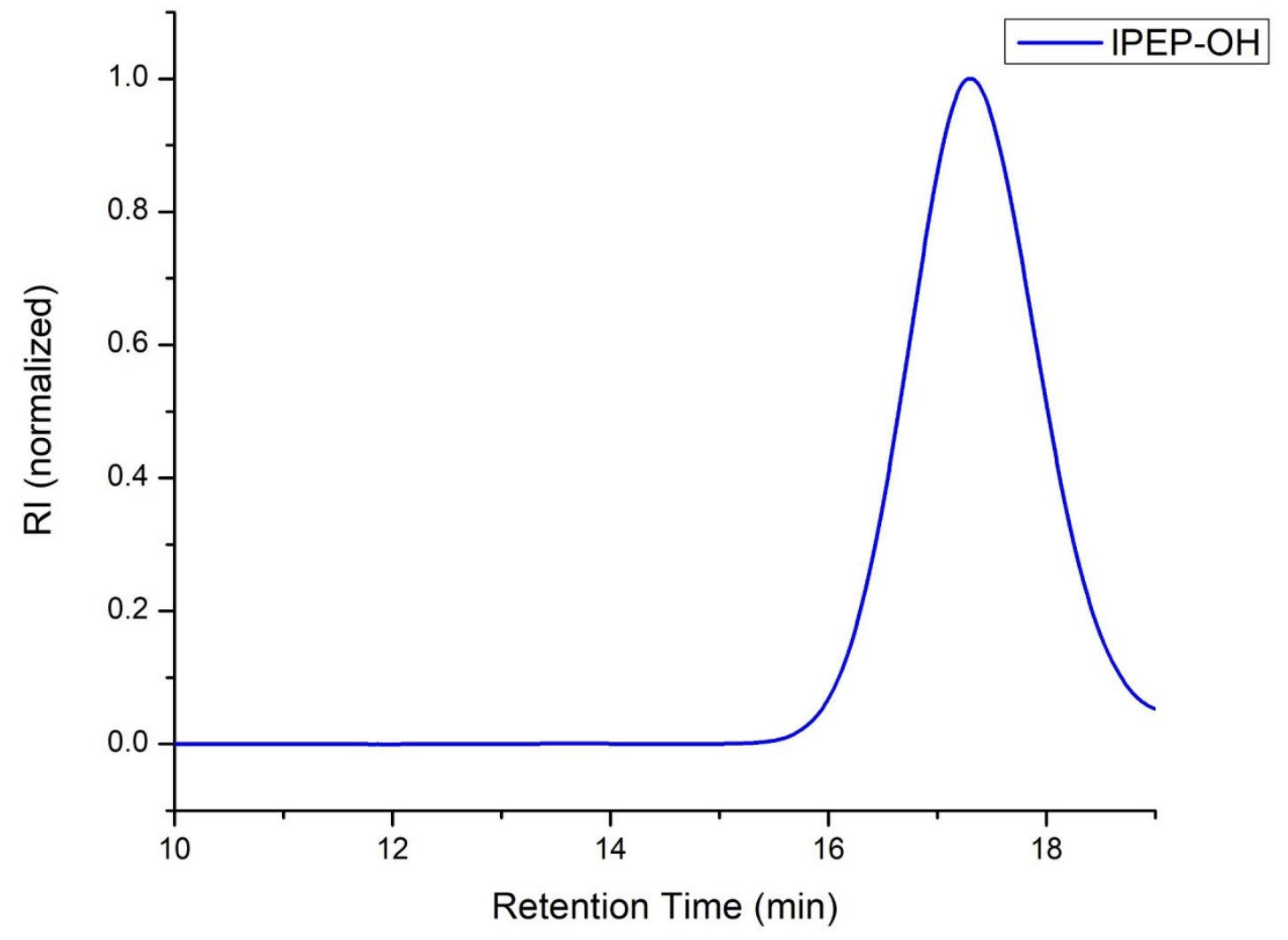

Figure S10. GPC trace of linear poly(4-ethynylphenol).

\section{Responsive solubility of cyclic and linear poly(4-ethynylphenol)}

$5.9 \mathrm{mg}$ poly(4-ethynylphenol) was dissolved in $100 \mu \mathrm{L}$ THF. 10 vials were prepared with $10 \mu \mathrm{L}$ of the polymer solution transferred into each vial using a micropipette. All the vials were then dried under vacuum overnight. Different $\mathrm{pH}$ solutions ranging from 4 to 14 were made using sodium hydroxide and hydrochloride acid. In each vial with dried poly(4-ethynylphenol), 1.000 $\mathrm{mL}$ of different $\mathrm{pH}$ solutions was added respectively to prepare 10 different polymer aqueous solutions with different $\mathrm{pH}$ values. The exact $\mathrm{pH}$ value of each solution was tested with a $\mathrm{pH}$ 
meter. UV-vis spectra of each polymer solution with different $\mathrm{pH}$ values were taken (cyclic: Figure 7; linear: Figure 11S). The absorbance at $294 \mathrm{~nm}$ of each solution was plotted against the $\mathrm{pH}$ values and the plots are included in Figure 8 (main article).

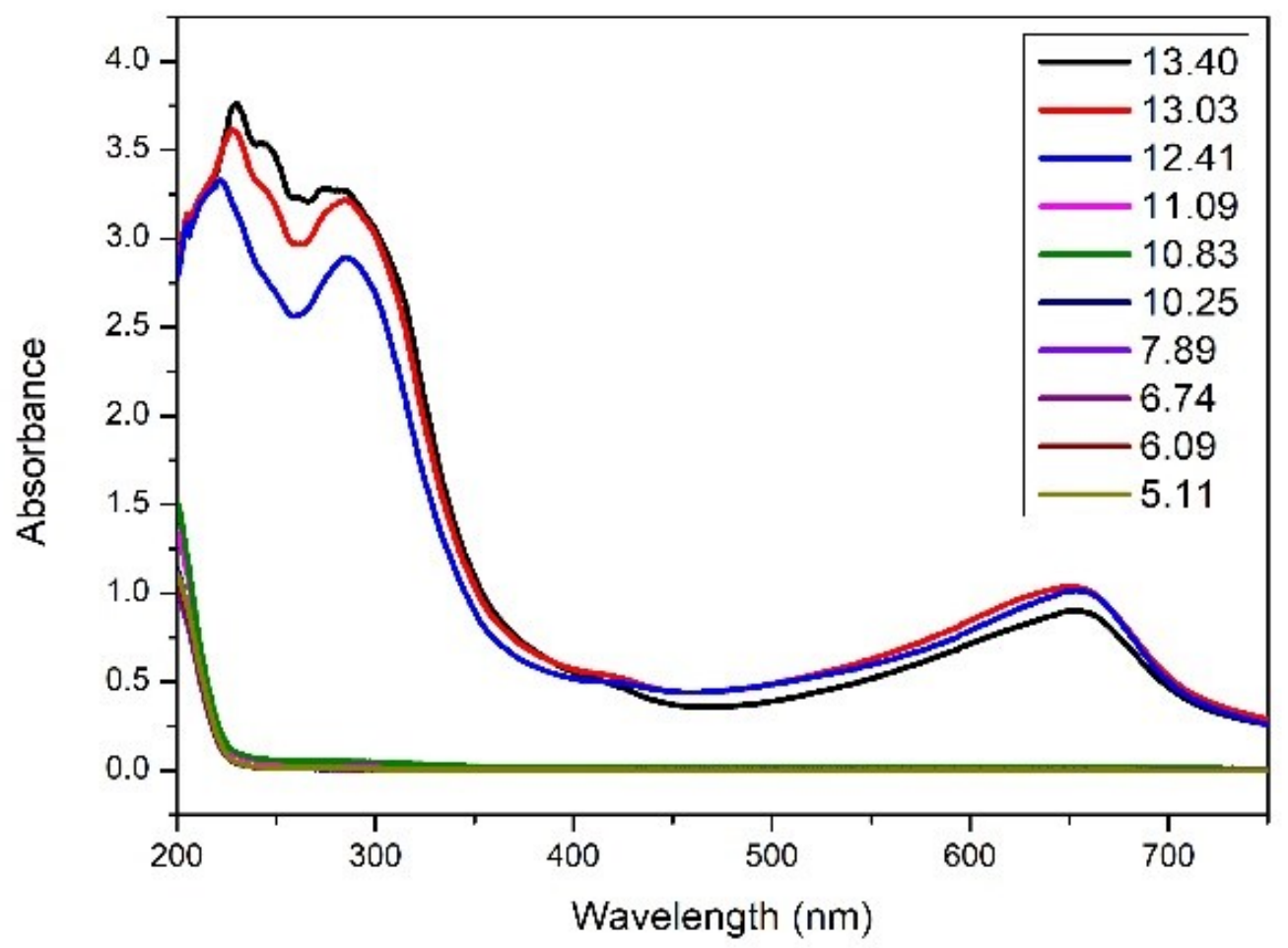

Figure S11. UV-vis spectra of linear poly(4-ethynylphenol) sample in different $\mathrm{pH}$ aqueous solutions. 
Table S1. $M_{n}, M_{w}$ and PDI values for linear and cyclic poly(4-ethynylanisole) and linear and cyclic poly(4-ethynylphenol).

\begin{tabular}{|l|l|l|l|}
\hline & $M_{\mathrm{n}}(\mathrm{Da})$ & $M_{\mathrm{w}}(\mathrm{Da})$ & $\emptyset$ \\
\hline Cyclic poly(4-ethynylanisole) & 96,500 & 138,300 & 1.43 \\
\hline Linear poly(4-ethynylanisole) & 79,300 & 126,800 & 1.60 \\
\hline Cyclic poly(4-ethynylphenol) & 86,900 & 102,500 & 1.18 \\
\hline Linear poly(4-ethynylphenol) & 72,300 & 101,900 & 1.41 \\
\hline
\end{tabular}

Reference:

1. Roland, C.; Li, H.; Abboud, K.; Wagener, K.; Veige, A., Cyclic polymers from alkynes. Nature Chemistry 2016, 8 (8), 791-796.

2. Trhlikova, O.; Zednik, J.; Balcar, H.; Brus, J.; Sedlacek, J., [Rh(cycloolefin)(acac)] complexes as catalysts of polymerization of aryl- and alkylacetylenes: Influence of cycloolefin ligand and reaction conditions. Journal of Molecular Catalysis a-Chemical 2013, 378, 57-66. 